\title{
Non-steroidal anti-inflammatory drugs and life threatening complications of peptic ulceration
}

\author{
C P ARMSTRONG AND A L BLOWER \\ From the Leighton Hospital, Leighton, Crewe, Cheshire
}

SUMMARY Two hundred and thirty five consecutive patients with a life threatening complication of peptic ulceration, who either died or required emergency surgery, have been studied over a 36 month period. Seventy eight of these high risk patients died; 25 at home, 19 in hospital without surgery and 34 postoperatively. Ninety eight patients had bleeding ulcers, 132 perforated ulcers and five had both bleeding and perforated ulcers. One hundred and forty one of these 235 patients $(60 \%)$ were taking a non-steroidal anti-inflammatory drugs (NSAID) and the individual agents have been listed. The overall incidence of NSAID use in a hospital control group was $9.9 \%$. The first sign of an ulcer was a life threatening complication in $58 \cdot 2 \%$ of patients taking a NSAID. Nearly $80 \%$ of all ulcer related deaths occurred in patients using an anti-inflammatory agent. Patients using these drugs were older, with more pre-existing medical conditions and had larger ulcers than those not taking NSAIDs. The mortality associated with a peptic ulcer complication in patients taking a NSAID was more than twice that in patients with no such drug history. There appears to be a relationship between the development of a life threatening complication of peptic ulceration and NSAID ingestion. Much of the associated mortality and morbidity may be potentially avoidable.

There is evidence of a recent reduction in the number of elective operations for chronic peptic ulcer. ${ }^{1-5}$ Nevertheless, peptic ulceration remains a serious problem and was responsible for nearly 14000 deaths in England and Wales over the years 1982-4. ' Of these ulcer related deaths 7000 were associated with bleeding and 5000 with perforation and threequarters of the mortality occurred in patients over the age of 70 years. "It has recently been reported that the incidence of perforated peptic ulcer is increasing in elderly men and women in contrast with a decrease in the younger age groups.' Non-steroidal antiinflammatory drugs (NSAID) have been associated both with the development of peptic ulceration and the life threatening complications of haemorrhage and perforation..$^{3 \times-12}$ As 22 million prescriptions for NSAIDs were issued in the United Kingdom in $1985^{7}$ their relationship to peptic ulceration requires urgent

Address for correspondence: Dr C P Armstrong. Leighton Hospital. Leighton. Crewe, CWI 4QJ. Cheshire.

Received for publication 21 August 1986. clarification. The aim of this study was to relate NSAID ingestion to all cases of peptic ulceration with perforation or bleeding who either died or underwent emergency surgery in a given area. We have selected only patients at high risk and the figures presented do not relate to all bleeding ulcers.

\section{Methods}

\section{PATIENTS}

This study analyses a consecutive series of 235 patients who either died as a result of, or required emergency surgery for, bleeding or perforation of a benign peptic ulcer between January 1983 and December 1985 (36 months). Information from the first six months was obtained by retrospective case note examination and from the last 30 months in a prospective manner. Patients were from the South Cheshire area which is served by Leighton Hospital and provides all acute services for a population of approximately 250000 . Those patients who died suddenly at home or in hospital before operation 
were only included when the diagnosis was confirmed at coroner's autopsy. In all other patients the diagnosis of benign peptic ulceration was confirmed at operation or by gastroscopy in two patients. Patients with gastric carcinoma were excluded as were those patients with bleeding ulcers who settled without surgical intervention.

A careful record was made by the admitting doctors of all drugs being taken on or within one month of admission and the length of use of these drugs was also noted. Patients were closely questioned for a history of dyspepsia of over one week duration and any pre-existing medical conditions. In those patients who died at home a drug and medical history was obtained from the general practitioner records.

During 1985 a consecutive group of 1246 patients admitted to hospital without peptic ulcer disease were directly questioned by the authors for drug use. Detail was obtained of all drugs used within one month of admission from the patients themselves or close relatives. These patients were not individually matched with subjects from the study group.

All patients who presented with haematemesis or melaena underwent gastroscopy within a short time of admission. Surgery was indicated in those patients with a bleeding ulcer by criteria similar to those of Hunt et $a l^{13}$ - that is, patients who were shocked on admission with a massive bleed, recurrent bleeding, a requirement of over 5 units of blood and in those patients where gastroscopy demonstrated stigmata of recent or concurrent bleeding. Patients with a perforated peptic ulcer underwent surgery except for a few cases where the clinical situation was very poor and a conservative policy was used.

The site and size of all ulcers was recorded from the operative or post mortem findings. The postoperative course was noted as was the length of stay in Intensive Care and hospital. Postoperative deaths were defined as those occurring in hospital or within 30 days and in such cases an attempt was made to find the exact cause of death, usually by autopsy. Statistical analysis was by the $\chi^{2}$ test, or Mann- Whitney $U$ test where appropriate.

\section{Results}

ALL PATIENTS

Of the 235 patients 124 were men and 111 women, with median ages of 66 and 76 years respectively. Forty two per cent of male patients and $70 \%$ of female were over 70 years of age. Fifty three patients had gastric ulcer complications: bleeding 26, perforation 24 , and three a combination of bleeding and perforation. One hundred and seventy nine patients had duodenal ulcer complications: bleeding
69, perforation 108 and two a combination. Three patients had bleeding from both duodenal and gastric ulcers. The incidence of perforation of peptic ulcer in this district was $17 \cdot 6 / 100000$ per year. The true incidence of bleeding peptic ulcer was not estimated as this study excluded patients who recovered without surgery. Seventy eight of the 235 patients died giving an overall mortality of $33.2 \%$. Twenty five patients died suddenly at home as a result of seven bleeds and 18 perforations and of these nine $(36 \%)$ were under the age of 70 years. Nineteen patients died in hospital without an operation as a result of nine bleeds and nine perforations with one patient having a combined bleed/perforation. Two patients with perforations were treated conservatively and survived. The remaining 189 patients underwent emergency surgery. Thus $56 \cdot 4 \%$ of peptic ulcer related deaths occurred without operative intervention.

\section{NSAID INGESTION}

One hundred and forty one patients $(60 \%)$ in the study group had a definite history of NSAID use before developing their complication of peptic ulceration. There was no difference in NSAID use between patients studied in a retrospective or prospective manner. Thirteen of these 141 patients were also on steroids and four other patients were receiving steroids only. Eighty patients received NSAIDs for osteoarthritis, 20 for rheumatoid arthritis, 12 for various other 'rheumatic' conditions and in 29 no obvious reason for NSAID ingestion could be identified. There was no relationship between the length of time of NSAID ingestion, which ranged from one week to over three years, and the development of bleeding or perforation. Likewise there were equal numbers of bleeding and perforated peptic ulcers in patients with rheumatoid and osteoarthritis. A history of dyspepsia before the acute event was obtained in $41.8 \%$ of patients using NSAIDs compared with $75.5 \%$ of patients not taking anti-inflammatory agents $\left(\chi^{2}=25.89, p<0.0001\right)$. An acute life threatening complication was the first sign of a peptic ulcer in $58 \cdot 2 \%$ of patients taking NSAIDs. In six patients taking NSAIDs a 'silent' perforation had been present for more than three days and this presentation was not seen in patients who had not used anti-inflammatory agents. The various drugs being taken on admission are listed in Table 1 and six patients were taking two different anti-inflammatory agents concurrently. Fifty nine patients taking NSAIDs had a definite history of dyspepsia and seven had been started on anti-ulcer medication for a proven peptic ulcer (cimetidine five, ranitidine two, in adequate dosage). Seventeen of 94 patients not using anti-inflammatory medication were on full 
Table 1 The relationship of individual NSAIDs to ulcer complications and deaths

\begin{tabular}{|c|c|c|c|c|c|}
\hline Drug & $\begin{array}{l}\text { Patients } \\
\text { (n) }\end{array}$ & $\begin{array}{l}\text { Bleeding } \\
\text { (deaths) } \\
\text { (n) }\end{array}$ & $\begin{array}{l}\text { Perfora- } \\
\text { tion } \\
\text { (deaths) } \\
\text { (n) }\end{array}$ & $\begin{array}{l}\text { Bleed/perf } \\
\text { (deaths) } \\
(n)\end{array}$ & $\begin{array}{l}\text { Deaths } \\
(n)\end{array}$ \\
\hline Piroxicam & $28 *+\dagger+\div$ & $8(5)$ & $18(5)$ & $2(1)$ & 11 \\
\hline Indomethacin & $19^{* * *+\dagger}$ & $9(5)$ & $10(2)$ & - & 7 \\
\hline Indocid R & 7 & $3(2)$ & $4(3)$ & - & 5 \\
\hline Suppository & $3^{*}+$ & $1(1)$ & $1(0)$ & $1(0)$ & 1 \\
\hline Osmosin (W) & 5 & - & $4(2)$ & $1(0)$ & 2 \\
\hline Ibuprofen & $22^{*}+\dagger$ & $10(4)$ & $12(6)$ & - & 10 \\
\hline Naproxen & $22^{* *}$ & $12(5)$ & $9(6)$ & $1(0)$ & 11 \\
\hline Diflunisal & $8+t$ & $5(3)$ & $3(2)$ & - & 5 \\
\hline Salicylate & $8^{* *}$ & $4(1)$ & $4(1)$ & - & 2 \\
\hline Diclofenac & $8^{*}+$ & $3(1)$ & $5(3)$ & - & 4 \\
\hline Ketoprofen & $4 t$ & $3(1)$ & $1(0)$ & - & 1 \\
\hline Fenbufen & $3^{*}$ & - & $3(2)$ & - & 2 \\
\hline Misccllancous & 10 & $4(0)$ & $6(2)$ & - & 2 \\
\hline $\begin{array}{l}\text { Prednisolone } \\
\text { only }\end{array}$ & 4 & $1(1)$ & $3(0)$ & - & 1 \\
\hline
\end{tabular}

*denotes patients taking two different NSAIDs; †patients taking steroids also. Miscellancous includes azapropazone (2), phenylbutazone (W) (2), indoprofen (W) (1), flurbiprofen (1), sulindac (1), tiaprofenic acid (1), fienclofenac (W) (1), and mefenamic acid (1). (W) Drugs withdrawn or licence suspended.

antiulcer medical therapy (cimetidine 13 , ranitidine four, in adequate dosage). Repeat prescriptions of NSAIDs had been given to 45 patients with a definite history of dyspepsia lasting more than one month, and to 20 of these patients with dyspepsia of longer than one year duration.

The incidence of NSAID use in the control group of hospital patients was $123 / 1246(9.9 \%)$. The individual anti-inflammatory agents used in three age groups are shown in Table 2. Non-steroidal antiinflammatory drug use was more commonly seen in the elderly patients. The use of other drugs of all other types was not significantly different between the control patients and the study group.

Patients receiving NSAIDs who developed a life

Table 2 The use of individual NSAIDs in the hospital control group

\begin{tabular}{llll}
\hline & \multicolumn{2}{l}{ Age $(y r)$} & \\
\cline { 2 - 4 } Drug & $<60$ & $60-69$ & $>70$ \\
$(n=310)$ & $(n=506)$ & $(n=430)$ \\
\hline Piroxicam & 2 & 6 & 5 \\
Indomethacin & 2 & 5 & 8 \\
Ibuprofen & 3 & 7 & 12 \\
Naproxen & 4 & 3 & 14 \\
Diflunisal & 2 & 2 & 2 \\
Diclofenac & 2 & 3 & 4 \\
Ketoprofen & 1 & 4 & 3 \\
Fenbufen & 2 & 6 & 4 \\
Miscellancous & 3 & $46(9 \cdot 1 \%)$ & $56(1.3 \cdot 0 \%)$ \\
Total & $21(6 \cdot 8 \%)$ & & \\
\hline
\end{tabular}

Table 3 The relationship between NSAID ingestion, age, sex, and mortality $(n=235)$

\begin{tabular}{|c|c|c|c|c|}
\hline \multirow[b]{2}{*}{ Age (yr) } & \multicolumn{2}{|c|}{$\begin{array}{l}\text { NSAID use } \\
(n=I 4 I)\end{array}$} & \multicolumn{2}{|c|}{$\begin{array}{l}\text { No NSAID use } \\
(n=94)\end{array}$} \\
\hline & Male & Female & Male & Fermale \\
\hline$<29$ & $1(1)$ & - & 7 & - \\
\hline $30-39$ & - & - & 9 & 1 \\
\hline 4()$-49$ & 1 & 1 & 7 & 3 \\
\hline $50-59$ & $6(2)$ & 3 & 11 & $5(1)$ \\
\hline 6()$-69$ & $16(4)$ & $16(8)$ & $13(2)$ & $3(1)$ \\
\hline $70-79$ & $20(10)$ & $39(14)$ & $15(5)$ & $8(3)$ \\
\hline$>80$ & $12(7)$ & $26(15)$ & $6(3)$ & $6(2)$ \\
\hline Total & $56(24)$ & $85(37)$ & $68(10)$ & $26(7)$ \\
\hline
\end{tabular}

Figures are number of patients; in parentheses number of deaths.

threatening complication were on average older than those not using these drugs with median ages of 74 years and 59 years respectively $\left(\chi^{2}=22 \cdot 8, p<0 \cdot 001\right)$. The incidence of pre-existing medical conditions was similar in the two groups except for cardiovascular disease which was twice as common in patients using NSAIDs. There were similar numbers of gastric and duodenal ulcers, perforation and haemorrhage in these patients. Table 3 relates NSAID use to age, sex, and overall mortality. The majority of patients using NSAIDs who developed perforation or bleeding were over 60 years of age and almost all the mortality was seen in these cases. The age range in patients not using NSAIDs was more equally distributed with mortality again being closely related to age. Women were more common than men in those patients taking anti-inflammatory agents whereas the converse was true in patients not using these drugs. The overall mortality was higher in patients using NSAIDs at $43.3 \% v 18 \cdot 1 \%\left(\chi^{2}=16 \cdot 12, \mathrm{p}<0 \cdot 001\right)$. This difference was marked in younger patients (mortality for $<69$ years $34.1 \%$ with NSAID use and $6 \cdot 8 \%$ with no NSAID history respectively) although mortality was still increased in the elderly (mortality for $>70$ years $47 \cdot 4 \%$ and $37 \cdot 1 \%$ respectively). Sixty one of the 78 deaths $(78.2 \%)$ occurred in patients using an anti-inflammatory drug.

Large ulcers ( $>2 \mathrm{~cm}$ diameter) were seen in $37.6 \%$ of patients using NSAIDs in contrast with $24.5 \%$ of those not using these drugs $\left(\chi^{2}=4.43, p<0.05\right)$. Two or more ulcers were seen in seven patients taking NSAIDs and in seven patients not taking these drugs.

\section{OPERATIONS}

One hundred and eighty nine patients underwent emergency surgery. The postoperative mortality was $18.0 \%$ and varied with age, the site of ulcer and the complication. Of 81 patients operated on for bleeding 43 were over 70 years of age with an operative mortality of $34.9 \%$ and 38 were under 70 years of age 
with a corresponding mortality of $7 \cdot 9 \%$. Of 104 patients operated for perforation 50 were over 70 years of age with an operative mortality of $22 \%$ compared with $9.3 \%$ in 54 patients under 70 years of age. There was a higher mortality associated with gastric ulcer complications than the corresponding duodenal ulcer emergencies and this was independent of age. Twenty six of the 34 postoperative deaths were considered by the pathologist to be related to medical causes, and in eight patients surgical factors appeared to be responsible for the deaths. The relationship of NSAID use to age, sex, and operative mortality is shown in Table 4. Patients using NSAIDs who had an operation for a peptic ulcer complication were older than those not taking these drugs with median ages of 73 years $v 59$ years $\left(\chi^{2}=19 \cdot 6\right.$, $p<0.001)$. These patients, within the constraints of this study, also had a higher incidence of pre-existing cardiovascular disease. The operative mortality in patients taking NSAIDs was $24.3 \%$ in contrast with $10.5 \%$ in patients not using these drugs $\left(\chi^{2}=6 \cdot 60\right.$, $\mathrm{p}<0.02)$ and this difference in mortality was particularly marked in patients less than 60 years of age. In both groups of patients operative deaths were closely related to age. The length of postoperative stay in survivors was similar in the two groups of patients with a mean \pm SD of $12 \cdot 3 \pm 7 \cdot 45$ days and $10 \cdot 9 \pm 5 \cdot 59$ days respectively.

\section{Discussion}

Although several epidemiological studies have reported a fall in the incidence of perforated peptic ulcer over the last decade ${ }^{+1+}$ the Registrar General's figures ${ }^{\text {t }}$ show the total number of patients dying from bleeding or perforation to have remained constant over the last three years. It is of interest and as yet unexplained that these same sources have identified a decreased number of perforations in men in contrast with an increase in women, with the elderly being particularly affected.' Upper gastrointestinal haemorrhage from peptic ulceration has in the same time period increased in incidence and this increase is exclusively in patients over the age of 60 years. ${ }^{15}$ The use of NSAIDs has been suggested as the prime reason for these epidemiological changes. ${ }^{3 x-1112} \mathrm{We}$ have specifically studied patients with serious complications of peptic ulceration who would normally require surgery for cure and this report, in contrast with other published material, has included all deaths related to peptic ulcer complications in a given area. The importance of including sudden deaths is emphasised as over half the total ulcer related mortality was accounted for by patients dying at home or in hospital before surgical intervention.

The incidence of perforation in this area was twice
Table 4 The relationship between NSAID ingestion, age, sex, and mortality in patients undergoing operation $(n=189)$

\begin{tabular}{llllll}
\hline & \multicolumn{3}{l}{$\begin{array}{l}\text { NSAID use } \\
(n=103)\end{array}$} & & \multicolumn{2}{l}{$\begin{array}{l}\text { NoNSAID use } \\
(n=86)\end{array}$} \\
\cline { 2 - 3 } \cline { 5 - 6 } Age $(y r)$ & Male & Female & & Male & Female \\
\hline$<29$ & $1(1)$ & - & 7 & - \\
$30-39$ & - & - & 9 & 1 \\
$40-49$ & 1 & 1 & 7 & 3 \\
$50-59$ & $5(1)$ & 3 & 11 & $5(1)$ \\
$60-69$ & 12 & $12(4)$ & & 11 & $3(1)$ \\
$70-79$ & $17(7)$ & $28(4)$ & & $13(3)$ & $6(1)$ \\
$>80$ & $9(4)$ & $14(4)$ & & $5(2)$ & $5(1)$ \\
Total & $45(13)$ & $58(12)$ & $63(5)$ & $23(4)$ \\
\hline
\end{tabular}

Figures are number of patients; in parentheses number of deaths.

that quoted in hospital based studies from Oxford ${ }^{3}$ and Ipswich ${ }^{x}$ and this may relate to our inclusion of all at home deaths. Furthermore the incidence of perforated ulcer is higher in the north-west than in the south of England. ${ }^{1+}$ The incidence of bleeding peptic ulcer has not been calculated as this study did not include the majority of patients with bleeding peptic ulcers who settled without surgery. Many of the patients in this study were elderly with women being significantly older than men. The overall mortality associated with a bleeding or perforated peptic ulcer was closely related to age as there was a three-fold greater chance of dying in patients over 70 years and deaths were rare under the age of 60 years. The mortality for gastric ulcer complications was almost twice that of duodenal ulcer emergencies confirming previous observations. ${ }^{1 / 6}$

The relationship of NSAIDs to peptic ulceration remains controversial as there is an increased incidence of peptic ulceration in rheumatoid arthritis but not in osteoarthritis. ${ }^{17}$ Non-steroidal antiinflammatory drugs inhibit the enzyme prostaglandin cyclo-oxygenase and thereby reduce the biosynthesis of prostaglandins in the stomach. This may compromise the efficacy of the gastric mucosal barrier and lead to mucosal damage. ${ }^{1 x-21}$ The use of individual anti-inflammatory agents has been related to the bleeding and perforation complications of peptic ulceration $^{7-4}$ and ulceration in more distant areas of the bowel has been reported with slow release preparations of NSAIDs. ${ }^{223}$ Recent studies, which did not include patients dying at home, have shown NSAID use in a large proportion of patients requiring emergency surgery for perforated ${ }^{3 \times 11}$ and bleeding $^{41215}$ peptic ulcers. In our study $60 \%$ of patients with life threatening complications of peptic ulceration had a definite history of NSAID use and it is of interest that a high proportion of these patients using NSAIDs were women. Most prescriptions were for osteoarthritis, rheumatoid disease and other rheu- 
matic disorders although in 29 patients no reason for NSAID use could be found despite a close scrutiny of their records. It is worrying that prescriptions for NSAIDs were repeatedly given to a large number of patients with a clear history of dyspepsia. We have listed the individual anti-inflammatory agents with piroxicam, indomethacin, ibuprofen and naproxen being the most common drugs associated with peptic ulcer emergencies. It is noteworthy that the incidence of NSAID use was far higher in the study group than in a control series from the same hospital although it must be remembered that detailed drug histories were often difficult to obtain from elderly subjects. Information from most patients was obtained prospectively and we could find no difference in NSAID use between these patients and those studied by case note examination. The same four anti-inflammatory agents were most commonly prescribed in the control group and from our figures piroxicam and indomethacin were the drugs with the greatest risk of complications. The potential dangers of NSAIDs are further illustrated as in $58.2 \%$ of patients using antiinflammatory agents an acute complication was the first symptom of peptic ulceration. Moreover 'silent' perforations were seen in six patients using these drugs, of whom three died. Ulcer complications, in the absence of a history of NSAID use, were seen in a minority of patients in this study and the majority of these cases had a long history of dyspepsia. This change in incidence from the 'classical' peptic ulcer to the acute drug induced ulcer has been noted by other authors. ${ }^{3+25}$

In this study $78.2 \%$ deaths occurred in patients using NSAIDs. Complications of peptic ulceration associated with NSAID use were accompanied by a considerably greater risk of death than the similar complications in patients who were not taking these medicines. These two groups were not comparable, however, as patients using NSAIDs were older with more pre-existing cardiovascular disease and this may account for the different mortality rates, and also our control group showed that NSAID use was more common in the elderly. Nevertheless we must remember that neither age nor cardiovascular disease caused the peptic ulcers. Several patients with 'classical' ulcers were receiving effective antiulcer medication at the time of their bleed or perforation and this confirms the inherent resistance of some peptic ulcers to medical therapy. ${ }^{32 n}$ A similar proportion of patients using NSAIDs were simultaneously taking anti-ulcer medication because of a dyspeptic history, thus questioning the value of $\mathrm{H}_{2}$-blocking agents in the treatment and prevention of NSAID induced ulcers." Where dyspepsia and peptic ulceration occurs with the use of NSAIDs then it would seem logical to try anti-ulcer drugs that enhance gastric prostaglandin activity with cytoprotection such as sucralfate and bismuth preparations. " 210 Our data on mortality, silent perforation, and ulcer size suggest that NSAID induced ulcers may be particularly dangerous, although this requires further investigation.

The operative mortality for bleeding ulcers requiring surgery in this study was similar to recent figures from Nottingham."* Gastric ulcers were more dangerous than duodenal and the operative mortality was increased by a factor of four in patients over 70 years confirming earlier reports. ${ }^{1+2 x}$ The operative mortality for perforations was closely related to the site of the ulcer and to age with most deaths occurring over the age of 80 years and with gastric ulcers. Patients who had an operation for bleeding or perforated peptic ulcer were more likely to die when there was a history of NSAID use and the higher operative mortality may relate to differences in age and pre-existing medical disease. It is noteworthy that four patients developed further ulcer complications related to NSAID use after vagotomy and gastrectomy suggesting that acid reducing surgical procedures do not protect the stomach and duodenum from these anti-inflammatory agents.

Life threatening complications of peptic ulceration are still common and are associated with a high mortality, especially in the elderly. Many patients died suddenly at home and these must be included in future studies. Sixty per cent of patients who developed peptic ulcer complications were using NSAIDs and in these patients an acute emergency was often the first sign of ulceration. Nearly fourfifths of all deaths occurred in patients using an antiinflammatory agent and we are at present investigating the prescribing frequency of the individual antiinflammatory agents in our area to determine their relative risks. In this study the use of NSAIDs appears to be related to the development of life threatening complications of peptic ulcer and many of the deaths and morbidity so caused may be potentially avoidable. The use of NSAIDs should be carefully controlled and these drugs should not be available 'over the counter' or used as simple analgesics. It is important for each clinician to assess the individual 'arthritic' patient to determine whether NSAID use is justified.

We would like to thank $\mathrm{Mr} \mathrm{J}$ F Clegg, Mr G B Rawsthorne, and Mr D Cade. Consultant Surgeons, for their help and advice. Mrs J A Newell and Mrs P Armor for secretarial help. Mrs J Farrell, Mrs I Bratt and their Medical Records Staff and Mr Price of the Cheshire Family Practitioner Committee for his help in tracing the deceased patients records. 


\section{Note}

The Committee on the Safety of Medicines have been notified.

\section{References}

1 Taylor TV. Deaths from peptic ulceration. $\mathrm{Br}$ Med J 1985; 291: 653-4.

2 Hirschowitz BI. Natural history of duodenal ulcer. Gastroenterology 1983; 85: 967-9.

3 Watkins RM, Dennison AR, Collin J. What has happened to perforated peptic ulcer? Br J Surg 1984; 71: 774-6.

4 Coggon D, Lambert P, Langman MJS. 20 years of hospital admissions for peptic ulcer in England and Wales. Lancet 1981 ; i: 1302-4.

5 Fineberg HV, Pearlman LA. Surgical treatment of peptic ulcer in the United States. Trends before and after the introduction of cimetidine. Lancet 1981; i: 1305-7.

6 Office of Population Censuses and Surveys. Deaths in England and Wales 1982-4. London: HMSO, 1985.

7 Walt R, Logan R, Katschinski B, Ashley J, Langman M. Rising frequency of ulcer perforation in elderly people in the United Kingdom. Lancet 1986; i: 489-92.

8 Collier DStJ, Pain JA. Non-steroidal anti-inflammatory drugs and peptic ulcer perforation. Gut 1985; 26: 359-63.

9 O'Brien JD, Burnham WR. Bleeding from peptic ulcers and use of non-steroidal anti-inflammatory drugs in the Romford area. Br Med J 1985; 291: 1609-10.

10 Kurata JH, Elashoff JD, Grossman MI. Inadequacy of the literature on the relationship between drugs, ulcers and gastrointestinal bleeding. Gastroenterology 1982; 82: 373-6.

11 Walker AJ, Dewar EP. Emergency peptic ulcer surgery - an association with NSAIDs. [Abstract] Gut 1985; 26: A1118.

12 Somerville K, Faulkner G, Langman M. Non-steroidal anti-inflammatory drugs and bleeding peptic ulcer. Lancet 1986; i: 462-4.

13 Hunt PS, Hansky J, Korman MG. Mortality in patients with haematemesis and melaena: a prospective study. Br Med J 1979; 1: 1238-40.
14 Barker DJP, Power C, Lambert PM, Smith CL. Perforated duodenal ulcer in England and Wales: time trends, and regional and urban - rural differences. Health Trends 1981 ; 13: 13-5.

15 Berry AR, Collin J, Frostick SP, Dudley NE, Morris PJ. Upper gastrointestinal haemorrhage in Oxford. $J R$ Coll Surg Edinb 1984; 29: 134-8.

16 Bonnevie, O. Survival in peptic ulcer. Gastroenterology 1978; 75: 1055-60.

17 Pemberton RE, Strand LJ. A review of uppergastrointestinal effects of the newer non-steroidal antiinflammatory agents. Dig Dis Sci 1979; 24: 53-64.

18 Hawkey CJ, Rampton DS. Prostaglandins and the gastrointestinal mucosa: are they important in its function, disease or treatment. Gastroenterology 1985; 89: $1162-88$.

19 Bjornason I, So A, Levi AJ, et al. Intestinal permeability and inflammatory changes in rheumatoid arthritis: effects of non-steroidal anti-inflammatory drugs. Lancet 1984; ii: 1171-5.

20 Stern AI. The gastric mucosal barrier. Med J Aust 1985; 142: $59-70$.

21 Davenport HW. The gastric mucosal barrier. Digestion 1972; 5: 162-5.

22 Day TK. Intestinal perforation associated with osmotic slow release indomethacin capsules. $\mathrm{Br} \mathrm{Med} J \mathrm{1983;287}$ : 1671-2.

23 Langman MJS, Morgan L, Worrall A. Use of antiinflammatory drugs by patients admitted with small or large bowel perforations and haemorrhage. $\mathrm{Br}$ Med $\mathrm{J}$ 1985; 290: 347-50.

24 Jorgensen TG. Drug consumption before perforation of a peptic ulcer. Br J Surg 1977; 64: 247-9.

25 Jacyna MR, Shepherd AN. Perforated ulcer in the elderly. Lancet 1985 ; ii: 1309.

26 Bardhan KD. Refractory duodenal ulcer. Gut 1984; 25: 711-7.

27 Davies J, Dixon AStJ, Beales JSM. The effect of cimetidine on peptic ulceration in patients receiving anti-inflammatory therapy. In: Wastell $\mathrm{C}$, Lance $\mathrm{P}$, eds. Cimetidine: the Westminster Symposium. Edinburgh: Churchill Livingstone, 1978: 275-80.

28 Dronfield MW, Atkinson M, Langman MJS. The effect of different operation policies on mortality from bleeding peptic ulcer. Lancet 1979; i: 1126-8. 